Vol. 17, No. 3, 15 de noviembre, 2018

\title{
Significados y representaciones de la minga para el pueblo indígena Pastos de Colombia
}

\section{Meanings and representations of the the minga for the Pastos people from Colombia}

\section{Oscar López Cortés}

Centro de Investigaciones Socio Jurídicas, Universidad Libre de Colombia, Bogotá, Colombia

oscarandreslopezcortes@gmail.com

Recibido: 29-abril-2018

Aceptado: 12-noviembre-2018

\section{RESUMEN}

Este artículo presenta una revisión de literatura sobre la minga y los resultados del trabajo etnográfico sobre este aspecto realizado con el pueblo indígena de los Pastos. Se indagó qué otros sentidos de la vida cotidiana se encuentran asociados a la minga para los Pastos. Los relatos recolectados muestran que la práctica de la minga entre los Pastos subvierte el espacio y el tiempo en los cuales la ubican los textos académicos. Se concluye que la minga, no es solo una forma de trabajo comunitario o un mecanismo de movilización social y acción política, sino que es una herramienta que mantiene la memoria histórica al renovar constantemente los vínculos intersubjetivos de quienes la practican.

Palabras clave: espacio, minga, movilización social, tiempo, trabajo comunitario

\section{ABSTRACT}

This paper exposes the literature review and the results of the ethnographic fieldwork with the Pastos people, both of them about a cultural practice called minga. It was inquired what others meanings of the Pastos people daily life are linked with the minga. The stories collected states that the practice of the minga among Pastos people undermines the space and the time in which literature locates the minga. The conclusion is that the minga is not only a shape of community labor or a strategy to social mobilization and political action, but a tool that preserves the historical memory through which there is a renewal of the intersubjectivities links of those practices it.

Keywords: community labor, minga, Pasto people, space, social movilization, time

Financiamiento: Universidad Libre de Colombia, Bogotá, Colombia

Cómo citar este artículo: Lopez Cortes, O. A. (2018). Significados y representaciones de la minga para el pueblo indígena Pastos de Colombia. Psicoperspectivas, 17(3), 1-13. http://dx.doi.org/10.5027/psicoperspectivas-vol17-issue3-fulltext-1353

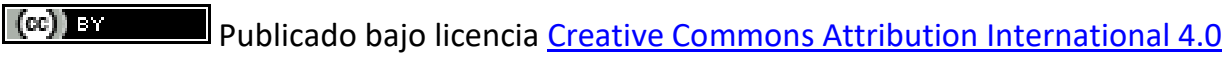


La expresión minga es asociada a formas de trabajo comunitario propio de las comunidades amerindias ubicadas en la cordillera de los Andes desde Chile hasta el Colombia. Como parte de los procesos de recuperación de la identidad cultura en los países andinos, la expresión minga ha sido reivindicada por movimientos sociales, colectivos académicos y organizaciones comunitarias en toda la región. En algunas de estas reivindicaciones, la minga adquiere el significado de trabajo solidario en comunidad opuesto al trabajo abstracto, muerto y alienado con el que ha sido cargado el producto de las relaciones capitalistas. En otras, la minga trasciende ese significado para ser representada como una forma de movilización social y acción política.

Sin embargo, cabe preguntarse si esas representaciones de la minga hacen justicia con el o los sentidos que esta expresión puede tener para las comunidades ancestrales. Incluso, es necesario indagar si a la expresión minga se le atribuye el mismo significado entre las diferentes comunidades indígenas de los Andes suramericanos. Sin embargo, lo que aquí se busca no es un ejercicio lingüístico, semiótico ni etimológico sobre la palabra minga; tampoco traducir la expresión para la comunidad académica.

El objetivo es divulgar los hallazgos obtenidos luego de investigar a propósito de la minga entre el pueblo indígena binacional de los Pastos, situados en la frontera entre Colombia y Ecuador. La pregunta que orientó esta indagación buscaba dilucidar qué otros sentidos o dimensiones de la vida cotidiana se encuentran asociados a la minga para los Pastos, esto, luego de que en varias conversaciones y entrevistas realizadas durante el trabajo de campo etnográfico con ese pueblo indígena surgieran diversos sentidos de la expresión. Para ello, primero se describe el método empleado y la manera como este ayuda a sostener las hipótesis de la indagación; luego se reconstruirán algunas posturas académicas sobre la minga como marco referencial de la discusión. En el tercer apartado se presentarán los resultados del trabajo etnográfico, que será seguido de la discusión, la cual buscará contrastar el marco referencia con los hallazgos del trabajo etnográfico a la luz del concepto de regímenes de representación.

Finalmente se plantearán algunas conclusiones. La hipótesis que guió la elaboración de este artículo es que la minga entre los Pastos permite comprender el tiempo de otra manera en la medida que ese fenómeno escapa de los regímenes de representación que buscan definirla, lo que trasciende la comprensión de esa práctica como una forma de organización económica y de protesta social.

\section{Método}

Como parte del proyecto de investigación, fueron revisados textos de diferentes disciplinas que ofrecieran análisis a propósito de la minga. Se privilegió aquellos que tuvieran algún tipo de aproximación empírica, de preferencia etnográfica. Los textos se discuten en este artículo a la luz de los resultados del trabajo de campo etnográfico adelantado por el autor entre 2007 y 2011. Como parte del trabajo de campo se realizaron 21 entrevistas a profundidad con líderes de diferentes edades pertenecientes al pueblo de los Pastos. Todas las personas entrevistadas viven en diferentes veredas del Resguardo del Gran Cumbal, ubicado en el departamento de Nariño (Colombia). Sin embargo, la mayor cantidad de información se deriva de la participación en los talleres llevados a cabo entre los años 2010 y 2011 en Cumbal con las autoridades del Consejo Mayor de Cumbal. También fueron analizados los documentos del archivo del cabildo, tales como el Plan Binacional para el fortalecimiento Cultural, Natural y Ambiental del Nudo de los Pastos, así como las actas que recogían las discusiones de las mesas de trabajo conformadas en el 2007 para la expedición de la Ley Interna del resguardo de Cumbal. Por último, como parte del trabajo etnográfico fueron sostenidas largas conversaciones con diferentes personas del resguardo en el ejercicio de acción participante realizado durante aquellos años.

El concepto teórico y metodológico clave que guió la lectura de los materiales de archivo, así como el análisis de la información recolectada en campo, fue el de "regímenes de representación" propuesto por Cristina Rojas y retomado por Arturo Escobar. En esa perspectiva teórica, los regímenes de representación serían lugares de construcción de la identidad así como de "encuentro de los lenguajes del pasado y del futuro, lenguajes externos e internos y lenguajes de sí y de los otros" (Escobar, 2014, p. 57).

Cristina Rojas construye su concepto de regímenes de representación a partir de autores como Bakhtin. De acuerdo con la lectura de Rojas (2001), Bakhtin señala que el autor, o sujeto que enuncia

define los lugares para el otro y también se asigna un lugar para sí mismo. El proceso de dotar de sentido a los fenómenos es también un proceso de incorporación de los fenómenos a una existencia espacio-temporal. El proceso de asignar valor a un fenómeno surge de su incorporación al tiempo y al espacio. (Rojas, 2001, p. 149)

La perspectiva teórica desde la cual se posiciona la lectura 
de los materiales, parte de comprender que, en la medida que algunos de los autores referenciados en el siguiente apartado asignan un sentido o definición a la minga limitada a su condición de trabajo comunitario, la introducen en unas coordenadas espacio temporales, o en otras palabras: le otorgan un tiempo y un espacio a la minga como fenómeno social. Sin embargo, y como lo demuestran otros autores, el fenómeno de la minga pareciera escapar a las coordenadas espacio temporales asignadas para deslizarse entre las disciplinas y sus definiciones hacia lugares y tiempos que trascienden la linealidad de los relatos. De esa forma, la minga escapa del régimen de representación que busca definirla entre los lenguajes del pasado: como la práctica ancestral del trabajo comunitario, y los lenguajes del futuro: como el fenómeno de movilización social y resistencia política que se atribuye a la minga.

\section{Los estudios sobre la minga}

Cauca y Nariño, ubicados en la esquina sur occidental de Colombia, son dos departamentos con amplia presencia de pueblos indígenas en el país. Allí habitan los nasa, quillacingas, awa, Pastos, misak, emberas, entre otros. En este territorio han surgido fuertes organizaciones indígenas como el Consejo Regional Indígena del Cauca (CRIC), Autoridades Indígenas del Sur Occidente (AISO) luego transformada en Autoridades Indígenas de Colombia (AICO), la Asociación de Cabildos Indígenas del Norte del Cauca (ACIN), entre otras. En esta región del país se han registrado las movilizaciones y luchas indígenas más significativas del país (Santamaria, 2008). En ambos departamentos la minga es una práctica cultural ampliamente conocida por comunidades indígenas y campesinas.

La minga, la chagra y el ayllu, son descritos en algunos trabajos de antropología (Murra, 1987; Uribe, 1988, 1999) como formas típicas del trabajo originadas en el periodo prehispánico que aún son parte de la vida de los pueblos indígenas de los Andes. La definición más común de la minga la inscribe en una forma de trabajo comunitario de origen ancestral, la cual ha sido recogida por otras disciplinas, incluyendo aproximaciones desde el derecho como las de Guerrero (1994) y más recientemente la de Chaves (2005).

Doumer Mamián ha trabajado con poblaciones indígenas y campesinas del departamento de Nariño durante más de treinta años. Él encontró en la década de los noventa un deterioro social y cultural entre el pueblo pasto. Según Mamian (1996). Este hecho colocó, de un lado, a algunas familias en una condición marginal cuya única alternativa fue la autosubsistencia, y del otro, a familias que habían ingresado a la "economía de atesoramiento y de mercado" (Mamián, 1996, p. 69), lo que les permitía producir excedentes. Entre ambos extremos, Mamián (1996) registra el surgimiento de una "economía de producción de subsistencia comunal, en la cual se produce para reproducir los requerimientos biológicos, pero sobre todo, para reproducir las condiciones culturales y sociales en los marcos de la autonomía comunal y las relaciones con otros" (p. 69). La aproximación de Mamián logra despojar a la minga de la mirada esencialista del indigenismo, para exponerla como alternativa de subsistencia colectiva, un hecho social fundado en el principio de reciprocidad que coexiste con las consecuencias del capitalismo. De esa forma, la minga no es ni una antítesis del capitalismo, ni una condición marginal del mismo, como tampoco una simple forma de trabajo comunitario; lugares todos desde los cuales la minga simplemente reafirmaría la condición hegemónica del capitalismo. Mamián restituye las condiciones históricas de la minga en el presente del pueblo pasto, y la manera como esta reproduce las condiciones socio culturales en el contexto de la autonomía comunal.

En los trabajos académicos de la primera década de este siglo la expresión "minga" se encontraba asociada de manera exclusiva a la idea de trabajo comunitario. Katime y Sarmiento (2005) registran a la minga como parte de la clasificación de las formas de economía solidaria en el departamento de Nariño. Para las autoras la minga es un trabajo comunitario en beneficio colectivo practicado por las comunidades rurales con el propósito de construir obras de infraestructura. De la definición, se destaca el carácter voluntario que congrega a quienes participan de la minga. Concluyen que debido a su condición de costumbre social, la minga no está regulada por una norma legal. Algo semejante se pueden registrar en el trabajo de Mora, Benavides, Pastas, Bedoya y De La Parra (2005), quienes destacan que al incluir la minga como una forma de trabajo solidario aceptada y reglamentada por el derecho nacional, se podrían garantizar condiciones económicas equitativas para quienes en ella intervienen.

Avalos y Castillo (2014), analizan la práctica de la minga en el Ecuador, como una antigua tradición de trabajo compartido y comunitario en procura de la utilidad social y el bien común. Los autores destacan que esta práctica ha despertado en años recientes el interés de organizaciones sociales campesinas e indígenas de ese país, como respuesta a las políticas neoliberales introducidas luego del consenso de Washington. La minga hace parte de las estrategias comunales dentro de la diversidad de formas que adquiere actualmente la economía popular y solidaria.

Ruiz, Hernández, Coca, Cantero y Campo (2008), destacan el papel que juega la minga entendida como trabajo 
colectivo propio de las comunidades andinas en el desarrollo de la infraestructura turística de base comunitaria. A partir del estudio etnográfico desarrollado por los autores en cinco comunidades del Ecuador, ellos encuentran que a través de las mingas y otras formas de organización y trabajo colectivo, las comunidades estudiadas han propuesto formas de turismo sustentable y autónomo.

Otras investigaciones realizadas en Ecuador (Avemañay, 2012) evidencian relaciones entre la minga y diferentes espacios de la cultura andina, para plantear la relación que existe entre aquella, en tanto espacio de trabajo colectivo, y la educación intercultural bilingüe en la provincia de Chimborazo. El autor señala que la minga es una práctica ancestral de la cultura quechua a través de la cual se expresa el arraigo, el "amor a la tierra" (Avemañay, 2012, p. 18) y se crea la cultura.

En un trabajo de 2009, Molina y Rosero se plantean una inquietante cuestión:

¿Cuáles son los imaginarios de la minga en las comunidades campesinas de ascendencia quillacinga, y su relación con el Derecho y la economía solidaria, en los corregimientos de Obonuco, Genoy, Jongovito, EI Encano, la Laguna Buesaquillo y Mocondino, del Municipio de Pasto? (Molina, \& Rosero, 2009, p. 200)

A partir de allí, las autoras afirman que en la actualidad la minga practicada por dichas poblaciones campesinas en aquellos corregimientos de la capital de Nariño, otorga fundamento a su identidad, al ser empleada "como una construcción narrativa y poética de lo público, en un esfuerzo por ejercer lo justo desde sus instituciones y sus prácticas sociales" (p. 200). Este trabajo constituye una notable excepción dentro de las aproximaciones académicas a la minga, pues al tomarla como una formación discursiva, logran encontrar otros sentidos inscritos en esta práctica ancestral. Las autoras trascienden el lugar común dentro del cual la minga queda reducida, o bien a una forma de trabajo comunitario o a una expresión política de movilización, para ver en ella un mecanismo de reivindicación de justicia social ejercido a través de las prácticas colectivas transmitidas en la tradición oral y las prácticas cotidianas.

Molina y Rosero concluyen que la minga "traza entre sus practicantes un nosotros temporal histórico (evocado desde la simbología preincaica y panandina), de donde surge el desprendimiento de las necesidades de lo privado para priorizar valores desde lo público, como la justicia y la solidaridad" (p. 207). Lamentablemente la idea del "nosotros temporal histórico" no se desarrolla suficientemente por las autoras, lo que deja abierta la cuestión a propósito del tipo de relación con el tiempo que las comunidades construyen a través de la minga, discusión que será retomada más adelante en este artículo.

En la segunda década de este siglo, los trabajos académicos trascienden con mayor énfasis el sentido de la minga como un asunto económico o de trabajo comunitario. Como muestra la investigación de González (2010), la minga es una forma de organización política propia del sur occidente colombiano. A través de ella, el pueblo indígena nasa ha logrado transformar las prácticas sociales y los sentidos culturales de una época. La minga indígena en el departamento del Cauca ha constituido un mecanismo de organización y reivindicación política multitudinaria, movilizando no solo a quienes se identifican étnicamente, sino a otros sectores de la población como el movimiento estudiantil, las organizaciones campesinas y obreras en apoyo a las luchas por el territorio y el reconocimiento de los derechos de los pueblos indígenas.

A propósito de esas mismas movilizaciones en el Cauca, Almendra (2009) sostiene que la Minga Social y Comunitaria y la Minga en Resistencia para la Defensa Integral del Territorio, llevadas a cabo por los nasa entre 2004 y 2008, generaron espacios de encuentro para integrantes de ese pueblo indígena dispersos en el territorio, a través de los cuales se promovió la comunicación y la reflexión colectiva. Las mingas, propiciaron la creación y el fortalecimiento de la red de emisoras indígenas y la concertación entre las comunidades.

En esta misma línea, Rozental (2009) destaca como, a través de la Minga de Resistencia Social y Comunitaria del año 2005, los pueblos indígenas en Colombia se opusieron a la firma del tratado de libre comercio con Estados Unidos, el cual se suscribió pese al rechazo de los movimientos sociales. En este ejercicio, el autor destaca la relación que existe entre la palabra y la minga, que en este caso, encarna la acción misma de los pueblos, y cómo este ejercicio político revitalizó los movimientos populares en Colombia durante la primera década de este siglo. El autor destaca que podría interpretarse la minga a una forma de marcha o manifestación popular, pero no es así. La minga sería la manera de nombrar un "proceso en movimiento y el trabajo de tejer con sabiduría un sentido común" (p. 52). De esta forma, Rozental propone un sentido más profundo y complejo de la minga en tanto acto de resistencia que trasciende el discurso, al invitar a la acción de largo plazo por objetivos políticos de mayor envergadura, como la recuperación del territorio, la autonomía alimentaria, el comercio justo, entre otros. 
Escobar (2011) presenta un balance de las principales conclusiones a propósito de la globalización y sus implicaciones construidas por los movimientos sociales y académicos durante la última década del siglo XX y la primera del XXI. Para ello, el autor toma como referente la minga social y comunitaria convocada por los pueblos indígenas en el Cauca durante el 2008, la cual se generó como oposición al modelo de desarrollo extractivista ${ }^{1}$ impulsado entonces por el gobierno de Uribe Vélez. A partir de la comparación del modelo colombiano con la propuesta del sumak kausay presente en la Constitución de Ecuador, Escobar expone la manera como la minga moviliza otros sentidos del desarrollo invisibles a causa del predominio del proyecto capitalista e imperial. Según Escobar, la minga demuestra que es posible encontrar otras formas de sustento, de relaciones sociales, de prácticas económicas y ecológicas, así como el diseño de políticas desde las cosmovisiones relacionales. (Escobar, 2011, p. 311)

A partir de la observación de la vida cotidiana de los trapiches paneleros en Supía, departamento de Caldas (Colombia), Jurado y Botero (2012) analizan la minga en estos entornos como un referente en la construcción de lo que ellas denominan la localidad y la socialización política a través del trabajo. Este texto constituye una excepción importante en materia geográfica para la minga, pues encuentra esta práctica en lugares ubicados fuera de sus territorios habituales. Las autoras se aproximan desde la psicología política a la manera como algunas comunidades campesinas agrupadas en la Cooperativa Multiactiva de Productores Paneleros de Supía (COIMPAS), así como la Asociación Indígena de Paneleros (AIPAN), han incorporado la minga en sus prácticas organizativas de trabajo comunitario. En esta perspectiva, se convalida la afirmación hecha por autores antes citados como Rozental o Avalos y Castillo, en tanto colectivos que no se auto identifican a partir de elementos étnicos, como los campesinos de Supía, incorporan en sus prácticas formas de economía popular de otros movimientos con los cuales conservan relaciones de cooperación en el territorio. Algo semejante a lo que encuentra Castaño (2013), en relación con la Minga de Resistencia Social y Comunitaria iniciada en el departamento del Cauca, que constituyó un parámetro de movilización que se extendió a otros movimientos, como el estudiantil.

López y Rojas (2015) plantean que la manera como la minga ha sido objeto de estudio en disciplinas como la economía y el derecho plantea un sesgo reduccionista, el cual oculta otros sentidos inscritos en esa práctica cultural. Mediante el trabajo etnográfico realizado con el pueblo de los Pastos, los autores señalan que la minga no requiere de una reglamentación legal, pues se encuentra inscrita en las prácticas cotidianas de los pueblos indígenas, a través de las cuales estos han pervivido históricamente.

Postura distinta se encuentra en el trabajo de Obando (2015), quien a partir de un estudio sociológico basado en revisión bibliográfica y aproximación etnográfica, plantea que la minga es un modelo de trabajo comunitario que hace parte del legado de las culturas andinas cuyo fundamento se encuentra en la reciprocidad. Gracias a las mingas se ha mejorado la infraestructura en Nariño, lo que para el autor justifica que el Estado deba intervenir la minga.

Mención aparte merece el texto publicado por la Asociación Curuinsi y el Instituto de Investigaciones de la Amazonía Peruana (2004). Reunidos en estas organizaciones, los autores emplean la minga como metodología y a la vez mecanismo para cuestionar la idea dominante de autoría del texto. El artículo expone los resultados de un proyecto de formación sobre desarrollo propio y saberes indígenas en la Amazonía peruana, el cual fue realizado a través de minga. Pero lo destacable no es solo eso. La autoría del texto no se atribuye a un individuo ni tampoco a un grupo en coautoría, sino al colectivo. Como un producto de la reflexión de un colectivo donde los individuos renuncian a los réditos académicos, como las citaciones en revistas indexadas y demás, el texto desafía las reglas de divulgación del conocimiento científico. Este texto puede considerarse como una manera performativa de presentar la minga, en tanto no simplemente se habla de ella, la viven en la práctica a través de un intercambio de saberes simétrico y un ejercicio de construcción y presentación colectiva del conocimiento. Otra nota distintiva del texto es que cuestiona la afirmación común que insiste en presentar la minga como una práctica propia de las culturas indígenas andinas, colocándola en el contexto de la Amazonía peruana.

La manera como se representa la minga en los trabajos académicos mantiene vigentes los límites del capitalismo, discurso en el que solo puede existir un afuera o un adentro respecto de él. Esta forma de representación de la minga niega su diferencia, la cual desarrolla una alteridad cultural propia, con sus condiciones históricas y discursivas particulares. Cabe preguntarse si cexisten otros sentidos o efectos de la minga que permita pensar por fuera de la lógica del capitalismo y comprenderla

\footnotetext{
${ }^{1}$ Para una definición de extractivismo y sus implicaciones se sugiere revisar Göbel y Ulloa (2014)
} 
como algo que no sea la oposición a este? En los siguientes apartados se expondrá la manera como la minga en la cosmovisión de los Pastos, no solo atiende a un proceso organizativo y de acción política; tampoco se experimenta como algo necesariamente opuesto al capitalismo. La minga entre los Pastos permite otorgar otros significados a algo que está más allá de la organización económica: la relación con el tiempo.

\section{Resultados}

\section{La minga entre los Pastos}

La diversidad de trabajos existentes demuestra que los estudios académicos sobre la minga publicados en años recientes han trascendido la comprensión que se tenía de esa práctica cultural como una forma de trabajo comunitario. Los múltiples sentidos otorgados a la minga, como protesta social, movilización y acción política, dan cuenta de la complejidad de esa práctica. Sin embargo, una constante en los trabajos expuestos, es que la minga se define por oposición a las prácticas e imposiciones del libre mercado y de la visión hegemónica de la globalización. Ya sea como una forma de trabajo comunitario o como una acción política, parece inevitable entender la minga sin oponerla a la lógica del capitalismo. El problema de esto es que al definirla de esa manera pareciera imposible pensar desde un afuera del capitalismo, conservando así para este un lugar privilegiado en la reflexión académica.

Para el pueblo indígena de los Pastos que habita Cumbal ${ }^{2}$, más que una forma de trabajo, la minga es un estar con los otros en la diversidad. Las primeras aproximaciones etnográficas realizadas en el marco de esta investigación indicaban que la minga entre los Pastos parecía estar perdiendo relevancia dentro del tejido social. Como ocurre con otras prácticas culturales, algunas personas en Cumbal consideran que la minga ha dejado de ser un referente en la construcción de la identidad, para tornarse en una forma anacrónica y esencialista. Incluso quienes buscan revitalizar la minga son partidarios de esa opinión. Esto señalaba don Fidel Chalparizal, un hombre mayor de la vereda Cuetial-Nazate, quien formó parte del cabildo como regidor y gobernador durante la década de los años ochenta del siglo XX:

'La minga se ha perdido porque en la misma vereda había personas que pagaban por el trabajo mediante el jornal, lo que entorpeció las costumbres ancestrales. Cada uno ya tenía sus propios recursos. Lo otro es que eran menos los habitantes y era más fácil la

\footnotetext{
2 Municipio del departamento de Nariño y resguardo indígena conformado por las veredas de: Guam, Tasmag, Cuaical, Quilismal, Cuetial-Nazate, Cuaspud y Llano de Piedras. Se encuentra ubicado en la
}

comprensión, hoy son nuevas costumbres, y el personal se ha tratado de civilizar y la costumbre de servidumbre a los vecinos ya no fue colaborativa. El que recogía decía yo no regalo mi trabajo.' (Entrevista personal, abril de 2008)

Otro viejo líder de la época de la liberación de las tierras señalaba años después lo siguiente:

'Pero por nuestra desorganización ha habido gente que se ha aprovechado de nuestra desorganización. Ha habido gente que ha invadido nuestro territorio y ha invadido nuestros usos y nuestras costumbres, ustedes se pueden dar cuenta que por el avance de la tecnología se están perdiendo los usos y las costumbres, por ejemplo más antes las mingas eran bien concurridas y ahora casi ni se ven más.' (Intervención de Salomón Cuaical en el taller realizado en el Llano de Piedras, junio de 2011)

Como plantean López y Rojas (2015) no hay una respuesta unívoca a propósito de lo que ha ocasionado la disminución de las mingas como forma de trabajo comunitario entre los Pastos. Entre las razones señaladas por algunos líderes de ese pueblo indígena, se encuentra el desinterés cada vez mayor de los jóvenes por las tradiciones de los mayores. Incluso, atribuyen esta circunstancia a la "aculturación" producida por un sistema educativo que solo incentiva conocimientos útiles para la vida en la ciudad, mediante programas académicos hechos por instituciones ignorantes de las necesidades y la cultura del pueblo pasto. La aculturación destruye las posibilidades de conservar las tradiciones propias, las formas de trabajo y los valores ancestrales, como el cuidado de la tierra, el equilibrio y la reciprocidad.

Para algunos líderes jóvenes, como Luis Humberto Alpala, las mingas disminuyeron a causa del ingreso masivo de dineros públicos producto del sistema de transferencias a los resguardos indígenas consagrado en la Constitución Política de 1991, lo que generó la disminución de la participación colectiva en obras de beneficio común ${ }^{3}$. La opinión de Luis Humberto Alpala es compartida por otros miembros de la comunidad, como se evidenció en el taller realizado en el Llano de Piedras:

'Bien saben que el gobierno nos viene rematando y nos quiere desaparecer como comunidades indígenas, nos desaparecen como comunidades indígenas y quedamos como campesinos aquí y ustedes deben de saber que los campesinos no tienen los mismos derechos que nosotros tenemos, y ponernos a renegar entre nosotros mismos, y comenzarnos a dividir... eso fortalece al gobierno no

zona sur del departamento y constituye frontera con el Ecuador.

${ }^{3}$ Conversación personal con Luis Humberto Alpala en enero de 2010. 
nos fortalecemos nosotros mismos. Si nosotros acá nos seguimos dividiendo y discutiendo por las platas de transferencia $o$ por cualquier cosa estamos fortaleciendo al gobierno para que el gobierno nos desaparezca.' (Intervención de un asistente al Taller del Llano de Piedras, junio de 2011)

Pese a que la minga como forma de trabajo comunitario pareciera languidecer, este hecho ha dado lugar a una resignificación de la minga como experiencia política y organizativa. Durante el trabajo de campo, diferentes miembros de la comunidad, de distintas edades y roles sociales, hablaban de las mingas de pensamiento para designar las reuniones organizativas y políticas en las cuales la comunidad delibera y toma decisiones trascendentales para la vida social. A través de estas se desarrolló la iniciativa de creación del reglamento interno, instrumento que recoge la forma de justicia propia basada en lo que el mismo pueblo pasto designa como derecho mayor.

Para Luís Humberto Alpala, las mingas de recuperación ocurridas durante los años ochenta del siglo $X X$, permitieron al pueblo de los Pastos liberar ${ }^{4}$ la tierra de la propiedad privada que sobre ella ostentaban terratenientes blancos amparados por el Estado. Él describe la minga como una acción colectiva donde cada participante asumía alguna tarea: unos guachaban ${ }^{5}$ la tierra, otros preparaban los alimentos, algunos vigilaban, mientras que otros construían pequeñas chozas. Se trataba de una forma de organización del trabajo político y la acción colectiva cuidadosamente dispuesta. Adicionalmente, las mingas de recuperación implicaban la designación de una comisión que debía presentarse ante las autoridades estatales para librar la batalla legal por la tierra, combinando así en la minga, acciones legales y de hecho en procura del objetivo (Rappaport, 2005).

Para los Pastos la minga es un principio de vida:

'Este principio es uno de los más importantes que se debe mantener dentro de la población, el cual enlaza la vivencia colectiva de un pueblo o comunidad la que soporta su trabajo de construcción de las casas, de sus shagras, de arreglos de los caminos, de generar un bienestar colectivo, por lo anterior se puede afirmar y a la vez se propone que la minga es y debe seguir siendo el camino por donde transite el quehacer colectivo. Decimos entonces que este principio desde nuestros tiempos antiguos, nos socializa, arroja el valor de vivir en sociedad, en una convivencia.' (Fragmento de las intervenciones producidas en las mesas de trabajo

\footnotetext{
${ }^{4}$ Esta es la manera como los pueblos indígenas en Colombia designan el proceso de recuperación de sus tierras ancestrales promovido desde la década de los setenta del siglo pasado, y que tuvo como epicentro los departamentos de Cauca y Nariño. Liberar la tierra no es solo recuperar el título jurídico sobre extensiones del territorio que estaban en manos
}

conformadas en el 2007 para la expedición de la Ley Interna)

Como parte de las mingas que tuvieron lugar en la primera década de este siglo en Cumbal, se construyó el Plan Binacional para el fortalecimiento Cultural, Natural y Ambiental del Nudo de los Pastos, elaborado por Asociación de Cabildos y Autoridades Tradicionales del Nudo de los Pastos SHAQUIÑAN (s.f.). El documento plantea los seis fundamentos de la educación propia para el pueblo de los Pastos, dentro de los cuales se incluye la minga. Estos elementos son identificados como "Células de concepción y transmisión de la educación indígena" ( $p$. 71), a saber: "1) el fogón y la familia, 2) la Shagra, los rituales y los calendarios solilunares, 3) la minga de trabajo, 4) la minga de pensamiento, 5) el territorio y 6) los centros o instituciones educativas" (p. 72).

Las shagras son definidas como "lugares, formas y espacios naturales y cósmicos" (p. 73), compuestas por las plantas que proveen el alimento y la medicina, tanto como por los conocimientos derivados de las prácticas agrícolas. En este elemento, los rituales y los calendarios solar y lunar constituyen las herramientas a través de las cuales se aprenden los conocimientos prácticos necesarios para el sostenimiento de la shagra. En el documento se destaca la relación entre la shagra y el conocimiento derivado de ella: no se trata de una forma abstracta de conocer que se puede dar en cualquier lugar, sino del conocimiento situado y mediado por una acción concreta: la minga. De allí que las reivindicaciones políticas más relevantes de los Pastos, como de muchos otros pueblos indígenas, sean la territorial y la autonomía alimentaria, pues sin el espacio necesario de la shagra y sin la posibilidad de conservar las semillas nativas y las técnicas tradicionales de cultivo a través de la minga, sería imposible preservar la vida y el conocimiento.

Por último, el documento contempla las mingas de trabajo y de conocimiento como fundamentos de la educación propia para el pueblo de los Pastos. A la primera, el Plan Binacional la describe de la siguiente forma:

Espacio y forma que consiste en la reunión de la comunidad para desarrollar actividades comunitarias, arreglo de caminos, construcción de obras, casas comunitarias, acueductos, puentes, reforestaciones, mantenimiento de vertientes de agua y otras actividades. En este espacio las comunidades además del trabajo unen y crean pensamiento, ideas $y$

de terratenientes, es además aliviarla de la ganadería extensiva, los monocultivos, los pesticidas y fungicidas químicos a los que la ha sometida el modelo desarrollista.

${ }^{5}$ Forma empleada para designar la actividad de preparación de la tierra para el cultivo. 
alternativas comunitarias futuras, dialogan alrededor del quehacer comunitario. (p. 73)

En esta descripción la minga coincide con las representaciones que de ella hacen gran parte de los trabajos académicos. En tanto que la minga de pensamiento resulta más innovadora. Según el mismo documento:

Consiste en las tradicionales reuniones de una parcialidad, comunidad o comunidades, que se congregan para pensar, coordinar y ejecutar acciones, planes, programas y proyectos en la búsqueda de satisfacer sus necesidades. Es el espacio del intercambio de saberes, de ofrecer y recibir conocimiento, de conocer y entender los temas, derechos y perspectivas de los pueblos. Es la célula comunitaria del diálogo, que se alimenta con la expresión oral, cuentos, danza, música autóctona, sainetes, exposiciones culturales, rituales (p. 74).

La minga para los Pastos trasciende la representación de trabajo comunitario y de movilización política. Las mingas de pensamiento encarnan un principio de vida basado en la reciprocidad y el estar con los otros en comunidad. A través de ella los Pastos construyen su reglamento interno, organizan el territorio y se posicionan políticamente. Pero la minga en el caso de los Pastos hace posible algo más: desafiar la forma historicista del tiempo, como se expondrá a continuación.

\section{Discusión y conclusión}

La minga, una disputa por el tiempo

Quizás el mayor potencial de la minga es el de ubicar el trabajo por fuera de la comprensión del tiempo que impone el capitalismo. Esto ocurre en tanto al asignar a la minga otros significados distintos al de trabajo comunitario, los Pastos hacen uso de un lenguaje descolonizador, y así, traspasan la frontera vigilada por las disciplinas de la economía y el derecho, mediante las cuales la minga es solo una forma de trabajo cooperativo que deja incólume una de las ideas centrales del liberalismo político: todo trabajo productivo genera valores de cambio, independiente de que estos sean repartidos de manera colectiva o individual.

Por ejemplo, la minga como reunión con fines deliberativos deja de ser un trabajo productivo para convertirse en una forma productora de tejido social. A través de la minga se construye el espacio comunitario mediante el cual se recrea la memoria y al tiempo se resignifican los sentidos de justicia presentes en las prácticas llevadas a cabo por la comunidad en sus actividades cotidianas. De esta manera lo resumía uno de los participantes del taller realizado en el Llano de Piedras:

\begin{abstract}
'Vamos a seguir avanzando de la mano con los cabildos, con nuestros consejos mayores, porque ahí es donde se marca la diferencia, ya se pasa de una administración tradicional a una administración en la que se trate de hacer lo propio, que se trate de una misma gobernabilidad de las comunidades, que se trate de establecer estos mismos procesos importantes, como son los reglamentos internos, los planes de salvaguarda, lo cual nos va a fortalecer y nos va a dar un desarrollo político a nuestras comunidades, para que de esta manera tengamos todos unas directrices claras, tengamos unas normas a qué sujetarnos y esas normas se las construyen en estas mingas de pensamiento, se las construye en estos escenarios liderada por nuestro cabildo, por nuestro consejo mayor y obviamente con el acompañamiento de todos y cada uno de nosotros, y es lo que se anda haciendo en esta minga de pensamiento.'
\end{abstract}

El reconocimiento de los derechos de los pueblos indígenas que se consolidó, entre otras maneras, a través de la Constitución del 91, permitió a esas comunidades acceder a recursos públicos y administrarlos de manera autónoma. Esto generó un importante avance en la búsqueda de la inclusión y la igualdad promovida por el Estado Social de Derecho. Sin embargo, como a menudo lo recuerdan los miembros de los pueblos indígenas en Colombia, el ingreso de recursos económicos a sus comunidades ha contribuido al aumento de las confrontaciones internas. Varios narradores Pastos señalan además que el ingreso de esos recursos ha provocado el abandono de la minga como práctica de trabajo comunitario.

Es probable que precisamente al disminuir la frecuencia con la cual se practicaba el trabajo comunitario, cuyo propósito era hacer una vía, un acueducto o una casa, la minga hubiese recobrado sentidos perdidos tras la necesidad material de la subsistencia colectiva. En la medida que las reformas jurídicas permitieron a los pueblos indígenas en Colombia acceder a recursos con los cuales adelantar obras de infraestructura, la minga se liberó de su reducido sentido económico. No hay manera de demostrar que la minga tenía los significados que hoy tiene antes de la conformación de los estados nación en Sur América. Mucho menos durante el imperio colonial. Tampoco resultó importante establecer ese aspecto para efectos de esta investigación. Lo destacable es la manera en que pueblos indígenas como los Pastos dotan de sentido a una práctica ancestral con el fin de posicionarse políticamente en el inmediato presente. Un ejemplo de este uso estratégico de la minga se encuentra en la manera como se recuerdan y se re-significan las luchas recientes de los Pastos. 
Mediante el trabajo de la memoria re-construida a través de las mingas de pensamiento, los Pastos impugnan la memoria oficial promovida por el estado nación, refuerzan los vínculos del individuo al grupo, reflexionan sobre el gobierno y la autoridad propia, consolidan la justicia indígena y cuestionan las condiciones de desigualdad, pobreza y consumo promovidas por el liberalismo económico. De esa forma desafían la forma tradicional de la memoria oficial, la del recuerdo ordenado cronológicamente que segmenta las etapas de la historia en colonia-república-estado multicultural. Mediante la evocación de la minga en distintos tiempos y lugares, los Pastos tratan sin solución de continuidad el proceso histórico que ha generado pobreza y desigualdad. Así, cuestionan el régimen de representación de la minga que la ubica entre un trabajo comunitario y una forma de movilización política en tiempos y espacios determinados.

A partir de Benjamin (2008) el historicismo ha estado determinado por la idea de un tiempo homogéneo vacío, a lo que Fabian (1983) denominó como la negación de la contemporaneidad, a través de la cual se construye una idea de tiempo lineal, progresivo y ascendente. Se trata de una concepción del tiempo histórico singular (Mitchell, 2000) por medio de la cual se crea una historia única mediante la organización de la multiplicidad dentro de una narrativa peculiar caracterizada por la progresión del principio de la razón humana, la racionalidad técnica y el poder sobre la naturaleza. Esta forma de comprender el tiempo da lugar a los regímenes de representación, de los cuales la minga escapa. Como tempranamente demostró Mamian (1996), en tanto la minga es una alternativa de subsistencia colectiva fundada en el principio de reciprocidad que coexiste con las consecuencias del capitalismo, no es ni una antítesis de éste, ni una condición marginal del mismo. En términos de Dussel (2004), sería una exterioridad alterativa, como lugar de esa potencialidad que representa suponer que aún hay muchas culturas que no han sido asimiladas por la modernidad occidental y se resisten al tiempo homogéneo vacío.

Un ejemplo de la manera como esto ocurre surgió a través del trabajo etnográfico. La manera como son recordadas las luchas de los años 80 en las mingas actuales, y cómo esas mismas luchas hoy son recordadas como mingas (aunque no exista evidencia de que en aquellos años se les designaba de esa manera) rompe la linealidad histórica. Las luchas de los ochenta son evocadas permanentemente por los Pastos, no solo como un pasado heroico, sino como un elemento clave de su identidad presente. Así, los relatos de la organización de las mingas están estrechamente asociados con la manera como se recuerda el pasado, dadas las implicaciones políticas que eso tiene. Es en este punto donde la relación entre la minga, como palabra que se torna en acción, y la historia oral de los Pastos, cuyas relaciones son expuestas en el trabajo de López (2016), adquiere un significado relevante. La minga es una estrategia a través de la cual el pueblo de los Pastos construye a través de la memoria oral una posición política reivindicativa frente al Estado nación. La minga es una práctica y una representación alternativa que transcurre en un lugar y tiempo concreto, propiciando la acción colectiva y la movilización política de pueblos indígenas a lo largo de la cordillera de los Andes. Debido a condiciones concretas que experimentan los distintos pueblos indígenas y campesinos allí ubicados, es imposible definir de manera unívoca la minga para todos esos pueblos. Esto obedece a que la minga es empleada y re significada de acuerdo a las necesidades concretas, a los desafíos políticos inmediatos, y a las transformaciones culturales que cada pueblo afronta. De esa forma, la minga constituye una representación dinámica del trabajo y la economía política, pero además, una forma de construir la temporalidad que no atiende a los mandatos oficiales de la memoria institucionalizada por las prácticas discursivas del estado nación.

Los relatos recolectados a través del trabajo etnográfico muestran que la práctica de la minga entre los Pastos subvierte el espacio y el tiempo en los cuales la ubican los textos académicos. En los relatos recogidos, las temporalidades entre un ahora o presente concreto se trenzaban constantemente con distintos pasados, algunos bastante remotos para la temporalidad occidental, pero determinantes para la historia presente y el futuro de la organización social y política de los Pastos. Esos tiempos pasados, son enunciados como "los tiempos de adelante", en los cuales la minga siempre está presente.

Múltiples disciplinas académicas presentan una tendencia a definir la minga de una manera simple $y$ unívoca, restándole poder y complejidad, despojándola de la multiplicidad de sentidos que posee en el uso cotidiano. Esto a su vez desconoce el conflicto entre las formas de concepción y organización capitalistas del trabajo presentes en el discurso económico y las formas de organización que caracterizan a los pueblos andinos. Producto de semejante aproximación, en la década pasada algunos autores coincidían en señalar que era necesario regular la minga a través de normativas legales que garantizaran una distribución equitativa del producto del trabajo. Si bien esta no parece ser una alternativa adecuada, como ya se discutió, no se puede desconocer que la minga también puede ser un mecanismo que ha dado lugar a la organización formal de cooperativas multiactivas y otras formas de economía solidaria 
reguladas por la ley (Jurado, \& Botero, 2012). Sería necesario investigar con mayor profundidad si estas formas asociativas se quedan en el aspecto económico o dan lugar a la configuración de principios de vida alterativos.

Como evidencian algunos de los trabajos expuestos, la minga posee una multiplicidad de sentidos entre los cuales el económico es solo uno más. Es posible que las mingas no sean actividades económicas en el sentido capitalista al que se ha reducido la economía en esta época, como también es necesario resaltar que las mingas implican actividades que pueden tener finalidades sociales y culturales que trascienden lo económico. Los autores revisados demuestran que la minga, en el caso de los movimientos indígenas en Colombia, posee una connotación política desarrollada como respuesta a la opresión, el despojo y la inequidad que el modelo capitalista ha ocasionado en el país, especialmente en detrimento de la autonomía alimentaria y territorial de los pueblos indígenas y campesinos.

La minga subsiste en la tradición oral de los Pastos como elemento de cohesión social y construcción de identidad; por ella, se tejen los vínculos entre los individuos y la tierra, al tiempo que se realiza la justicia material. Recíprocamente, la minga mantiene viva la memoria histórica al renovar constantemente los vínculos intersubjetivos ligados por la resistencia contra la proletarización y expropiación de la tierra. Es por esto que no se puede desconocer que las comunidades andinas han dado a la minga la dimensión de categoría política. Se trata de una vivencia, de una experiencia que, mirada en términos de práctica social, regula el trabajo, pero también, la vida de pueblos andinos como los Pastos.

\section{Referencias}

Almendra, V. (2009) La palabra y acción para la movilización. Revista Comunicación y Ciudadanía, 2(2), 42-51.

Asociación Curuinsi, \& Instituto de Investigaciones de la Amazonía Peruana. (2004). Komuilla Uai, desarrollo propio y formación: Una minga urbana en la Amazonía peruana. Revista Nómadas, 41, 26 43.

Avalos-Reyes, J., \& del Castillo, L. (2014). La economía popular y solidaria: Una respuesta a las políticas neoliberales. Observatorio de la Economía Latinoamericana, 198.

Avemañay, A. (2012). La minga comunitaria del pueblo indígena y su aporte a la educación intercultural bilingüe: Estudio de caso del centro educativo comunitaria Estanislao Zambrano de la comunidad
Columbe Grande, Cantón Colta, Provincia de Chimborazo. Quito, Ecuador: Universidad Politécnica Salesiana.

Benjamin, W. (2008). Sobre el concepto de historia. En: W. Benjamin, Tesis sobre la historia y otros fragmentos. Itaca, México: Universidad Autónoma de la Ciudad de México.

Castaño, A. (2013). La minga de resistencia social y conunitaria: Construcción de un proyecto de movilización popular bajo lógicas de articulación intersectoriales. Santiago de Cali, Colombia: Universidad ICESI.

Chávez, G. (2004). El derecho a ser: diversidad, identidad y cambio: Etnografía jurídica indígena y afroecuatoriana. Quito, Ecuador: Flacso.

Departamento Nacional de Planeación (DNP), \& Asociación de Cabildos y/o autoridades tradicionales indígenas del Nudo de los Pastos Shaquiñan. (s.f.) Plan binacional para el fortalecimiento natural, cultural y ambiental del Nudo de la Wuaka o de los Pastos. Bogotá, Colombia: DNP. Disponible en https://redprodepaz.metabiblioteca.com/cgibin/koha/opacimageviewer.pl?biblionumber $=2656$

Dussel, E. (2004). Sistema mundo y transmodernidad. En: S. Dube, I. Banerjee \& W. Mignolo, (Eds.), Modernidades coloniales. México, D. F.: El Colegio de México.

Escobar, A. (2011). Una minga para el posdesarrollo. Signo y Pensamiento, 30(58), 306-312.

Escobar, A. (1998). La invención del tercer mundo: Construcción y deconstrucción del desarrollo. Bogotá, Colombia: Editorial Norma.

Fabian, J. (1983). Time and the other: How Anthropology makes its object. New York, NY: Columbia University Press.

González, C. (2010). Naturaleza política y acciones colectivas de los movimientos sociales, un emblemático caso de movilización indígena. Revista Universitas Humanística, 70, 79-100.

Göbel, B., \& Ulloa, A. (2014). Colombia y el extractivismo en América Latina. En: B. Göbel, \& A. Ulloa, (Eds.), Extractivismo minero en Colombia y América Latina. Bogotá, Colombia: Iber-Amerikanisches Institut y Universidad Nacional de Colombia.

Guerrero, G. (1994). Compendio de derecho laboral: Introducción y parte general. Bogotá, Colombia: Editorial Leyer.

Jurado, C., \& Botero, P. (2012). Trapiche, minga y resistencia: Una experiencia de socilalización política. Eleuthera, 7, 167-192.

Katime, A., \& Sarmiento, A. (2005). Hacia la construcción del derecho solidario en Colombia. Medellín: Universidad Cooperativa de Colombia, Dansocial. 
López, O. (2016). Narrativas académicas e historia oral en el pueblo de los Pastos. Antípoda, Revista de Antropología y Arqueología, 25, 77-98.

López, O., \& Rojas T. (2015). Entre leyes, mingas e historia oral. Controversia, 205, 219-271.

Mamian, D. (1996) Geografía Humana de Colombia, Región Andina Central, Tomo IV Volumen I.: Instituto Colombiano de Cultura Hispánica. Bogotá

Mitchell, T. (2000). The stage of modernity. En: Questions of modernity. Minneapolis, MN: University of Minnesota Press.

Molina, D., \& Rosero, M. (2009). Los discursos de la multiculturalidad en la formación de instituciones simbólicas de lo público: La minga de los pueblos del sur de Colombia. Revista Nacional de Investigaciones - Memorias, 25(12)

Mora, E. Benavides, M. Pastas, M. Bedoya, R., \& De La Parra, P. (2005). La minga, como entidad autóctona del derecho y de la economía solidaria. (tesis de pregrado), Universidad Cooperativa, Pasto, Colombia.

Murra, J. V. (1987). El control vertical de un máximo de pisos ecológicos en la economía de las socie- dades andinas. En J. V. Murra, (Ed.), Visita de la Provincia de León de Huánuco, Perú, Tomo II. Huánuco, Perú: Universidad Nacional H. Valdizán.

Obando, J. (2015). La minga: Un instrumento vivo para el desarrollo comunitario. Revista de Sociologia, 4, 82-100.

Oviedo, R. (2005). Relaciones y visitas de tasación en las tierras altas del Departamento de Nariño, durante el siglo XVI Pasto, Alcaldía Municipal de Pasto, Dirección de Cultura y Universidad de Nariño, Departamento de Sociología.

Rappaport, J. (2005). Cumbe Renaciente: Una historia etnográfica andina. Bogotá, Colombia: ICANH.

Rojas, C. (2001). Civilización y violencia: la búsqueda de la identidad en el siglo XIX en Colombia. Bogotá, Colombia: Editorial Norma.

Rozental, M. (2009). ¿Qué palabra camina la Minga? Deslinde, 45, 50-59.

Ruiz, E., Hernández, M., Coca, A., Cantero, P., \& Del Campo, A. (2008). Turismo comunitario en Ecuador: Comprendiendo el community-based tourism desde la comunidad. Pasos, 6(3), 399-418.

Santamaría, A. (2008). Estrategias políticas y estrategias jurídicas múltiples: La defensa de las víctimas del norte del Cauca colombiano. En: A. Santamaría, B. Bosa, E. Wittersheim, (Eds.), Luchas indígenas y trayectorias poscoloniales. Bogotá. Colombia: Universidad del Rosario.

Uribe, M. (1999). Las sociedades del Norte de los Andes. En: Historia General de América Latina, Vol. I: Las sociedades originarias. Madrid, España: Trotta, UNESCO.

Uribe, M. (1986). La estratificación social entre los ProtoPasto. En: J. Alcina Franch, \& S. Moreno Yañez, (Comps.), Arqueología y etnohistoria del sur de Colombia y Norte del Ecuador. Quito, Ecuador: Banco Central del Ecuador, Ediciones Abya-Yala 